Session 3661

\title{
STARTING AN INTEGRATED HUMANITIES/SOCIAL SCIENCE PROGRAM FOR AN ENGINEERING CURRICULUM: CURRICULUM AND COURSE DESIGN
}

\author{
Melvin Cherno \\ Division of Technology, Culture, and Communication \\ School of Engineering and Applied Science \\ University of Virginia
}

Anyone interested in establishing a cross-disciplinary program that integrates the humanities and social sciences into an undergraduate engineering curriculum will have to make at least four major decisions. This paper offers some advice based on the experiences of the Division of Technology, Culture, and Communication at the University of Virginia.

The new criteria for accrediting programs in engineering in the United States, announced as "Engineering Criteria 2000" by the Accreditation Board for Engineering and Technology, demand that graduates have a wide range of abilities and understandings, about half of which are based on knowledge transmitted by the humanities and social sciences; among these are "an understanding of professional and ethical responsibility," "an ability to communicate effectively," "the broad education necessary to understand the impact of engineering solutions in a global and societal context," and "a knowledge of contemporary issues." To meet the new ABET requirements, the new program will have to integrate engineering/technology with humanities/social science expertise and not merely expect engineering students to take--in a vacuum--a number of humanities and social science courses.

The TCC Division has for two generations established courses that serve this integrative purpose. Our courses are in three tiers, in all of which communications skills are wedded to learning about the connections between engineering and broader culture. TCC 101, a course taken in the student's very first semester in the Engineering School, combines instruction in written and oral communication with an introduction to the role engineers play within the university and within modern society. A TCC 200-level course is taken in the student's fourth semester; the student may choose from among over a dozen courses, all of which continue to stress oral and written communication but also relate engineering and technology to the broader society, one way or another, and serve additionally to introduce the student to the professional ways of thinking of practitioners of the humanities and social sciences. TCC 401 and 402, taught in the senior year, concentrate heavily on the role engineering and technology have played in western society, now and in the past; both are suffused with consideration of the subject of professional engineering ethics, allowing the student to put into perspective not only the ethical bases of his future career but also his responsibilities as a student and researcher. The latter role is important, because imbedded in 401/402, as a superintegrative experience, is the required undergraduate thesis, a research effort managed by the student in conjunction with a TCC and a technical adviser that places the engineering research in a context of professional responsibility. 
For maximum effectiveness, the new program should be created by a cross-disciplinary group of faculty members, representing as many humanities/social science perspectives as possible. These faculty members, even if they are intensely devoted to cross-disciplinary work, will inevitably wish to pursue their independent research programs as well and have the opportunity to use their narrower professional expertise in their teaching; faculty members will not want to deny their own specialized training and interests and should not be expected to do so.

The Division has taken special care to provide for both these aspects--the pooling of individual interests and the maintenance of separate teaching/research programs. TCC 101, 401, and 402 are multi-sectioned courses, in the planning and teaching of which all Division members are expected to participate by contributing from the vantage point of their own discipline. It is the 200-level courses that allow faculty members to explore topics more independently, in accord with their research interests, develop courses on these topics, and give undergraduate students more intensive "hands-on" experience in the methods and professional attitudes of their own disciplines.

III

A somewhat related issue arises in the case of the multi-section courses themselves. Even there some kind of compromise will be needed between the desire to establish a common syllabus and the need to accommodate individual differences in the faculty's abilities, teaching styles, and interests.

The Division has long since learned to distinguish between the overall syllabus of one of these multi-sectioned courses and instructors' individual syllabuses. The important thing is to provide both commonality and flexibility, for the good of individual faculty members, of students, and of the health of the curriculum itself.

IV

Our curriculum is very highly focused; not only the multi-sectioned courses, but the 200level courses as well are very specifically oriented to engineering- and technology-related topics. This focus no doubt satisfies the ABET integrative requirements, but it is clear that there is more to the world of the liberal arts than their relation to engineering and technology. The desire on the part of most faculty members in the humanities and social sciences, even those involved in an integrative engineering-related curriculum, will inevitably be to see to it that engineering students themselves profit by engaging in the intellectual pursuits of the rest of the university and by being exposed to the liberal arts as taught there.

On this issue also the Division has reached a compromise. The engineering-integrated program, as outlined earlier, normally comprises four of the student's courses. Another four to six courses in general education are taken in the more conventional manner; that is, students take 
these courses in the College of Arts and Sciences. For the most part they select these A/S courses simply by following their own interests; the only operating stipulations are that the courses must be culturally or intellectually broadening and that at least two of them must form a sequence of some kind. In our judgment this distinction between the TCC courses and the A/S general education electives not only serves the students best but also makes clear the distinct nature (and hence the distinct value) of the TCC requirements. 